\title{
Commentary: "IDEAS" and the IPS
}

Krishna A. Kumar*

Kerala Institute of Medical Sciences (KIMS), India

Article Info

\section{Article Notes}

Received: January 2, 2018

Accepted: February 13, 2019

\section{*Correspondence:}

Dr. Krishna A. Kumar, Professor and Hon. Senior Consultant, Kerala Institute of Medical Sciences (KIMS), Anayara,

Thiruvananthapuram 695 029, India; Email: drkakumar@ gmail.com.

(c) 2019 Kumar KA. This article is distributed under the terms of the Creative Commons Attribution 4.0 International License.

\section{Keywords}

Psychiatric Disability

Assessment

IDEAS

IPS

\section{Abstract}

Welfare programs for the disabled individuals have been carried out in many countries, in accordance with UNCRPD, through legislative measures. The social and political developments in India enabled legislation for such measures in India. To avail benefits under such welfare schemes, the degree of their psychosocial disability needs to be assessed quantitatively through valid, reliable and workable instruments. Though Chronic Mentally ill persons were included as a beneficiary group, under the Persons With Disabilities Act 1995 in India, lack of a quantified scale for psychiatric disabilities, deprived the benefits to the mentally ill, available to other category of disabled persons. This prompted the IPS in 2001, to develop a Scale for Psychiatric Disability as a time - bound one year prime project. The IDEAS Scale, thus developed, could get approval from Government of India, as the official Scale for Psychiatric Disability in India, soon after its release by IPS, through effective liaison with Administrators in Government. The internal consistency, face validity, content validity, reliability, comparability with WHO Scale, and utility and utilization for Disability Assistance Programs have all been established through studies since 2005 .The stigma on the mentally ill persons, though not totally eliminated, also got attenuated through inclusion in the spectrum of disabled individuals, covered by welfare and rehablititation programmes. The Rights of Persons with Disabilities Act 2016 (RPWD 2016) and the Mental Health Care Act 2017 (MHC Act 2017) are new legislative measures, implemented in India for the welfare of mentally ill persons. In the wake of these legislations there has been renewed interest, and concerted efforts in IPS to evolve guidelines for effective use of IDEAS and standardization of Disability Certification procedures. The time bound commitment of IPS in 2001, to develop IDEAS and getting its official acceptance by Government of India, through effective liaison, and the renewed interest and present concerted efforts to utilize it for helping large number of disabled chronic mentally ill, form sequential precious contributions for Community Mental Health in India. It seems an inspiring imitable model for professional Mental Health Organizations in other countries, probably with relevance in other health-care disciplines as well.

\section{Abbreviations}

IPS : Indian Psychiatric Society

IDEAS : Indian Disability Evaluation and Assessment Scale

UNCRPD : United Nations Convention for Rights of Persons with Disabilities

WHODAS 2.0: World Health Organization Disability Assessment Schedule- 2.0

RPWDA 2016: Rights of Persons With Disabilities Act 2016

MHC Act2017: Mental Health Care Act 2017

Commentary: "IDEAS" and the IPS 1

Rehabilitation, as a viable and vibrant medical discipline and 
social endeavor, began in the middle of Twentieth Century ${ }^{2,3}$. Loco motor disabilities, visual handicaps, Speech \& Hearing impairment, Mental Retardation and Multiple Disabilities emerged as the thrust areas in Disability Spectrum for clinical care and social support interventions. Apart from programs for restitution measures, training and sheltered employment, the disabled persons were given financial assistance through welfare programs in many countries.

In India, for nearly quarter century, after gaining its independence, the prime objective and thrust in the healthcare programmes were on enhancing hospital facilities for the management of lethal infections and other acute fatal conditions. Mortality of many medical conditions could be brought down through these measures, but survivors with disabilities and handicaps were added on to the tens of thousands of individuals with congenital and acquired disabilities, struggling to live in a society, with no systems or services for their care, support and rehabilitation. The Healthcare planners and Government functionaries perceived the existence and miserable plight of these unfortunate handicapped individuals in the community. It was also recognized that such programmes would be more effective, if managed by the Social Welfare Ministry, in collaboration with Health Ministry in the Government.

The social and political developments in India at that time were also favorable to the growing awareness about underprivileged, marginalized and disabled citizens in different sectors and segments of the society. The Social Psyche in India, has always had a compassionate component towards the sick, infirmed and disabled people.

The concept and message of evolving a Welfare State was gaining momentum in the public mind, echelons of Administration in the Government and in the Political Leadership, that imbibes ideas from the public mind, and takes up governance and runs the Government.

By Nineteen Seventies, the felt-need for evolving Rehabilitation programmes gathered momentum in Healthcare sector, Social Welfare Sector and started to impact the Planning and Policy making Sectors in the Union Government of India. The Social Welfare Ministry was renamed as the Ministry for Social Defense and Empowerment, and got designated as the Nodal Agency for all programmes for the support and rehabilitation of individuals with disabilities. The development of Rehabilitation as a vibrant medical discipline and social endeavor in the developed countries of the West, that started post World War-II, and gained momentum by Nineteen Seventies, and the United Nations' initiatives to uphold Human Rights of Persons with Disability inspired medical professionals, in various Medical Specialties, who are called upon to care the individuals with diverse disabilities. They transmitted this inspiration and ideas about rehabilitation to the Administrators, Planners and Political Executives who had already been sensitized about the felt-need for such programs in the public mind in a Welfare State. As a culmination of these social and political developments, increasing awareness about the need of Legislating for rehabilitation and welfare programmes for the disabled persons, gathered momentum in society, in Nineteen Eighties and Nineties. Community Based Rehabilitation (CBR) emerged as a major socio-medical initiative, implemented through Governmental and quasigovernmental programs, with active participation of Non-Government Organizations (NGO) in India. Financial assistance for individuals with major disabilities, financial support for Non-Governmental Organizations extending service to the disabled persons and reservation in educational institutions and job recruitments were the other legislative measures taken up by the Government, and implemented through the State (Provincial) Governments.

Visual, Speech \& Hearing, Loco- motor Disabilities, Mental Retardation and Multiple Disabilities were regarded as major disabilities. National Programs and National Institutions for addressing the training and rehabilitation needs of persons with these disabilities were established. Chronic Mental patients were not included anywhere in the ambit of these programmes ${ }^{4}$. Some leading psychiatrists in India and the Indian Psychiatric Society, (the professional organization of Indian Psychiatrists) kept on communicating the extreme disabled profile and miserable plight of chronic mentally ill persons to the Administrators and pleaded for including them in the scope of the governmental programs for the disabled persons. In 1995 the Person with Disabilities Act (PWD Act 1995) was passed by the Parliament of India, which was implemented all over the Country as Law. The Act provides for many welfare programs for the disabled, that include financial assistance, reservation in educational institutions and employment, and other benefits. Chronic mentally ill was included as one, (the last) category of Beneficiaries, in the list of Disabilities covered under the Act, thanks to the efforts of the Indian Psychiatric Society, and the empathy and good will of the Legislatures ${ }^{5}$.

However, this legislative inclusion did not get translated into any meaningful action for helping the mentally ill persons or their families. For Loco-motor Disability, Visual Handicap, Speech \& Hearing Disability and Mental Retardation there were scales for measuring and quantifying disabilities, and governmental assistance and considerations have been based on the percentage of disability, linked to the score obtained, applying these scales. Lack of such a quantified scale for measuring psychiatric disability, impeded the implementation of the provisions of the PWD Act for the benefit of chronic 
mentally ill persons with disability. Lacking such a scale for measuring and grading psychiatric disability, indeed, remained a stumbling block in harnessing the benefits of PWD Act 1995, on par with individuals with physical disabilities.

It was in the context that the IPS, in its National Conference at Pune in 2001, took the initiative to resolve the matter. Development of a quantified scale for assessing and grading Psychiatric Disability, was announced by the President as the Prime Project for the year. Rehabilitation Psychiatry Section of the organization was entrusted with the task of developing the Scale. The Chairperson, the Convener and the Members of the Rehabilitation Psychiatry Section has had high degree of expertise in, and commitment, to Psychiatric Rehabilitation. It has been well recognized that the perception of psychiatric disability should not confine itself to residual features of the disease, but should also include disabilities in the area of self care, communication and social relatedness, which from the major part of handicap caused by psychiatric disability. WHO Disability Assessment Scale (WHODAS 2.0 $)^{6,7}$ and DSM Global Assessment Functions (GAF) ${ }^{8}$ both have such a broad-based holistic approach, incorporating these variables. These existing scales were considered as references for preparing the Scale, but the guiding principle was to incorporate clinical and socio-cultural variables relevant in the Indian Context. Utmost care, not to overinclude cases in the Disability Scale was also taken, while evolving the Scale. The committee acted swiftly in concert with the Central Office of the IPS to develop the Scale. The developed Scale was successfully field- tested and validated in eight centers (out of ten centers planned) in different parts of the Country. The project was financed by the IPS, and carried out most economically by the dedicated members of the Rehabilitation Psychiatry Section and the investigators. The validated instrument was released as the Indian Disability Evaluation and Assessment Scale (IDEAS) in the next National Annual Conference at Kolkata in January 2002, as the official Psychiatry Disability Scale of the IPS, fulfilling the promise made by the President and office-bearers, while taking it up as the Prime Project for the year $2001^{9}$.

Aware of the importance of liaising with, and harnessing the support of Bureaucrats and Political Executives on the matter, the President, Secretary and Office Bearers of the IPS, kept interacting and lobbying with the former, in tandem with the development of the Scale. The IDEAS Scale, Scoring sheet, and write up about its development and validation of the Scale were presented and explained to many key persons in the Social Welfare Ministry, Government of India. These efforts bore fruition. On $27^{\text {th }}$ February 2002, within six weeks of the release of IDEAS by the IPS, Government of India, through an Extra-ordinary
Gazette, declared IDEAS as the official scale for evaluating and grading Psychiatric Disability in the Country ${ }^{10,11}$.

A Professional Organization, could not have achieved anything more precious or gratifying than this. Neither before, nor after this, any professional medical organizations in India, has had made a contribution of comparable significance and dimension to the welfare of patient populations served by its members.

With the acceptance of IDEAS, as the Official Scale, chronic mentally ill persons gained a recognition and status, on par with physical disabilities and Mental Retardation in governmental schemes for treatment, rehabilitation and social support. The psychiatrists in India and the IPS did recognize that this achievement does not address to, and eliminate the stigma of mental illness that the chronically mentally ill persons have to bear in society. In fact, any disability imposes a stigma on a person, which applies to mental illness also. However, the mentally ill person has to bear the additional burden of stigma on account of mental illness per se. Welfare programmes and empowerment through rehabilitation measures attenuates the stigma of the disabled persons and help in mainstreaming them into the social process. This facilitation and social empowerment were denied to the mentally ill persons, prior to the genesis of IDEAS, and its approval by the Government of India. It was hoped that the inclusion of the mentally ill in the spectrum of disabled persons, effected through IDEAS and its approval as official scale for quantifying psychiatric disability, would attenuate, though not eliminate the stigma, the mentally ill persons suffered in the community of disabled persons, as well as in society. With more and more persons with psychiatric disability coming forward to avail the social welfare and rehabilitation facilities, they get a mitigation of the stigma of exclusion and gain an acceptance in society, denied to them hitherto. In short, while IDEAS have not totally eliminated the stigma of the mentally ill, it helped in reducing to some extent the burden of stigma befalling them, prior to its genesis.

Applying IDEAS needs brief training for Mental Health Workers, which was provided by State Branches of IPS. A person, estimated as having forty percent disability or more, as per the scoring system in the Scale is eligible for financial assistance and reservation in education and employment (subject to eligibility and suitability for the job). Though the IDEAS released by IPS, includes duration of illness in the scoring schedule, this has been omitted by the Government. Similarly the periodic re-certification (once in five years) that was proposed in IDEAS Scale by the IPS was excluded in the Government Order, probably for reasons of logistics. While the Indian Psychiatric Society envisaged administration of IDEAS and scoring by all mental health workers with due training; Government of India mandated its administration and scoring by psychiatrists 
only, possibly to ensure professional authenticity and accountability $^{11}$.

In developing countries, the Governmental and Public funding agencies struggle to finance social welfare programs, and unless the Professional Bodies, liaise with, and lobby for such programs and provide workable operational instruments, no welfare measures can be fairly and effectively implemented. The development of a simple quantified scale for Psychiatric Disability, and getting it approved as official Scale for governmental programs for welfare schemes for chronic mentally ill, the IPS effected a qualitative achievement and quantum leap in the field of Psycho-social Rehabilitation in India.

The expectation that this milestone achievement would set in motion a concerted, nation-wide effort to identity and enroll chronic mentally ill in the ambit of Disability assistance scheme did not materialize fully for about ten years. Since 2010, the situation started changing. Psychiatric Disability assessment and certification have gained renewed interest and activities in India since then Many investigators have studied the internal consistency ${ }^{12}$, validity $^{13,14,15}$, comparability ${ }^{16}$ and utility ${ }^{17}$ of IDEAS Scale and its utilization ${ }^{18,19}$. The IDEAS evolved in a short time frame and approved by the Government of India has stood the test of time and scientific scrutiny.

The Rights of Persons with Disabilities Act $2016^{20,21}$ and the Mental Health Care Act $2017^{22}$ have been important legislative measures incorporating principles of UNCRPD ${ }^{23}$, and addressed to the care of mentally ill. The broad-based consultations during the incubation period of six to seven years of both these Acts, especially the former, kindled the IPS to reaffirm its commitment to the cause of Psychiatric Disability and Certification. The Rehabilitation Specialty Section of the Indian Psychiatric Society conducted workshops in 2018 with wide participation of mental health experts, and prepared consensus recommendations for using IDEAS more effectively, and laying guidelines for Certification Procedures (John. T \& Subramaniam. A -- Personal Communication). The renewed interest and enthusiasm shown by psychiatrists in the country, under the aegis of the IPS is heartening to all those concerned with welfare of the unfortunate mentally ill persons in the Country.

The genesis of IDEAS, effecting its approval by the Government, validating its merit, enhancing its utilization and refining its application by the Indian Psychiatric Society form precious contributions in the field of Rehabilitation and Community Mental Health in India. It also provides an imitable inspiring model for effecting welfare programs for chronic patients in other health care realms in India, and possibly in other countries as well.

\section{References}

1. Krishna A Kumar. “IDEAS and the IPS", Indian. J Psychiatry. January March 2017; 59(1): 124

2. Conti AA. Western Medical Rehabilitation through Time - A Historical and Epistemological Review - The Scientific World Journal, Published 14 January 2014 Volume 2014. https://dx.doi. org./10.1155/2014/432506

3. Rossler W. Psychiatric Rehabilitation Today: an Overview, World Psychiatry. 2006 Oct; 5(3): 151-157.

4. Disability: the concept and related Indian Legislations, Mental Health Review 2004. http://www.psyplexus.com/mhr/disability.india.html

5. Persons with Disabilities Act (Equal opportunities, Protection of Rights and Full participation) Act 1995. http://www.disabilityaffairs. gov.in/upload/uploadfiles/PWD_Act.pdf

6. World Health Organization : International Classification of Impairment, Disability \& Handicaps (ICIDH),Geneva : World Health Organization 1980. https://who.int/iris/handle/10665/41003

7. World Health Organization Classification of Functioning, Disability and Functions (ICF),Geneva: World Health Organization 2001, updated on $2^{\text {nd }}$ March 2018. https:/who.int/classifications /icf/en/

8. Assessment for rating Global Assessment of Functioning (GAF) NCBI - NIH. http://www.ncbi.nim.nih.gov.articles/

9. Indian Disability Evaluation and Assessment Scale (IDEAS) - A Scale of measuring and quantifying disability in mental disorders in India : Rehabilitation Committee, Indian Psychiatric Society : 2002, H Quarters: Indian Psychiatric Society, 43, Sector -55,Gurgaon Haryana India. http://www.indianpsychiatry.org/cpg/cpg2009/articles3.pdf

10. Guidelines for evaluation and assessment of mental illness and procedure for certification: Ministry of Social Justice and Empowerment, Government of India 2002, February 27. https:// socialjustice.nic.in/disabled/mentguide.html

11. Haque NS, Prakash R, Praharaj SK, et al Certification in Psychiatry. http://www.indianpsychiatry.org/cpg/cpg2009/article 3.pdf

12. Grover S, Shah R, Kulhara P, et al. Internal Consistency and Validity of Indian Disability Evaluation \& Assessment Scale (IDEAS) in patients with Schizophrenia. Indian J Med Re. 2014 Nov; 140(5): 637-643.

13. Sahoo S, Grover S, Dua D, et al. Concurrent Validity of IDEAS : Sociiooccupational functioning Scale in patients with Schizophrenia. Indian J Psychiatry. 2017 Jan - March; 59(1): 106-110.

14. Pal HR, Saxera S, Chandrasekhar K, et al Issues Related to Disability in India: a focus group study. National Med Journal India .2000 Sept Oct; 13 (5): 237 - 41.

15. Sadath A, Kumar S, Mathew S. Mental Disorders and Disability A Cross - sectional study of disability variance in severe mental disorders. Indian J Social Psychiatry. 2018; Volume: 34: 52-56.

16. Basavarajappa C, Sivakumar T. Disability Certification in Indian : IDEAS Vs WHODAS. Indian Psychiatric Med. Sept - Oct 2017; 39(5): $15-716$.

17. Mohan L, Tandon R, Kaltra H, et al. Disability Assistance in Mental Illness using Indian Disability Evaluation and Assessment Scale (IDEAS). Indian Med Res. June 2005; 121: 759 - 763.

18. Kumar SG, Das A, Bhantary PV, et al. Prevalence and pattern of mental disability using Indian Disability evaluation assessment Scale in a rural community in Karnataka Indian. J Psychiatry. 2008 Jan - March; 50(1): $21-23$.

19. Kashyap K, Thunga R, Rao AK, et al. Trends of utilization of Government Disability benefits among chronic mentally ill. Indian J Psychiatry: Jan - March 2012; 54(1): 54 - 58. 
20. The Rights of Persons with Disability Act 2016, Gazette of India (extra ordinary) 28 Dec 2016. http://www.disabilityaffairs.gov.in/Upload/ uploadedfiles/files/RPWD/Act/2 016.pdf

21. Narayan CL, John T. The Rights of Persons with Disability Act 2016: Does it address the needs of persons with mental illness and their families Indian. J Psychiatry 2017; 59: (17 - 20).
22. The Mental Health Care Act 2017, Ministry of Law and Justice, Government of India. https://www/egazette.nic.in/write Read Data/2017/175248.pdf

23. United Nations Convention on the Rights of Persons with Disability (UNCRPD) 2017. http://www/unorg/development/desa/ disabilities/convention-on-therights of- persons-with-disabilities. html 